\title{
Determining the utility of an unmanned ground vehicle for weed control in specialty crop systems
}

\author{
Matthew A. Cutulle, Joe Mari Maja \\ Clemson University, Coastal Research and Education Center, Charleston, SC, USA
}

\begin{abstract}
Highlights
- Specialty crop production is labor-intensive and vulnerable to rising labor expenses.

- Robotic weeders are promising weed control tools, with fewer environmental and human health risks.
\end{abstract}

\begin{abstract}
Specialty crop herbicides are not a target for herbicide discovery programs, and many of these crops do not have access to relevant herbicides. High-value fruit and vegetable crops represent high potential liability in the case of herbicide-induced crop damage and low acres for revenue. Labour shortages and higher manual weeding costs are an issue for both conventional and organic specialty crop growers. Robotic weeders are promising new weed control tools for specialty crops because they are cheaper to develop and, with fewer environmental and human health risks, are less regulated than herbicides. However, many of the robotic weeders are too expensive for small growers to use. In the future, greater investment into robotic weeders for small-scale growers will be important. The Clearpath robotics platform Husky may provide a cheap and autonomous way to control weeds in small diversified specialty crop farms. Being able to work autonomously in multiple soil moisture environments is the driving factor behind optimizing the Husky platform for weed control. Research has been conducted to evaluate the impact of soil moisture and mechanical actuator on mobility and weed control. Though weed control was
\end{abstract}

Correspondence: Matthew A. Cutulle, Clemson University, Coastal Research and Education Center, Charleston, SC, USA. E-mail: mcutull@clemson.edu

Key words: Robotic weed control; unmanned ground vehicles; specialty crops.

Received for publication: 10 March 2021.

Revision received: 10 May 2021.

Accepted for publication: 17 May 2021.

(C) Copyright: the Author(s), 2021

Licensee PAGEPress, Italy

Italian Journal of Agronomy 2021; 16:1865

doi:10.4081/ija.2021.1865

This article is distributed under the terms of the Creative Commons Attribution Noncommercial License (by-nc 4.0) which permits any noncommercial use, distribution, and reproduction in any medium, provided the original author(s) and source are credited. not commercially acceptable in these studies, future optimizations to the Husky robotics platform can achieve commercial success.

\section{Introduction}

Vegetables, including leafy greens and cole (i.e., Brassicaceae) and sweet potato crops, are extremely valuable commodities in the United States (US). For example, in 2016, fresh spinach was worth an estimated \$282 million (USDA NASS, 2020). Recent economic estimates suggest that broccoli, cabbage, and cauliflower gross per-acre values are \$6800, \$8630, and $\$ 10,500$, respectively (USDA NASS, 2020). In addition, sweet potato production was valued at over $\$ 600,000,000$ (USDA NASS, 2020). Consequently, growers invest significant amounts of time, energy, and financial resources towards weed control in preserving yield quantity and quality.

In vegetables, herbicide options are limited for conventional growers and almost completely unavailable in organic production systems; thus organic growers mainly utilize cultural practices combined with hand weeding to attain weed control (Mennan, 2009). Many of the chemical tools currently recommended for use in leafy greens, sweet potato, cucurbit crops, and brassicas do not provide a full spectrum of weed control or may be difficult to acquire due to cost and required application certification and burdensome to use due to re-entry interval or consumer perceptions. Results from a 2021 survey of New York growers attending a cole crop IPM workshop indicated that only $18 \%$ believed they successfully managed weeds with their current control programs (personal communication with Lynn Sosnoskie). The lack of effective herbicides, coupled with regulatory restrictions, and a growing public desire for vegetables produced with fewer pesticide inputs, necessitates research and extension-based programs focused on non-chemical weed control (Ditlevenson et al., 2020). This is particularly true in regions where high annual rainfall enhances incrop weed competition, which can be a limiting factor for producing annual specialty crops (Cutulle et al., 2019).

When discussing the current status of chemical weed control in agronomic crops, herbicide resistance is an overwhelming concern for growers. Thus, these commodity groups are interested in investigate the potential for non-chemical weed control strategies. Regarding non-chemical weed control, two key areas for expanded research and innovation include automated weeders and a con- 
comitant focus on identifying desirable crop varieties adapted to novel mechanical weeding mechanisms.

Automated weeders are employed in selected crops in the Salinas and Imperial Valleys of California and Arizona (Fennimore and Cutulle, 2019). Growers are adopting this technology partly because of limited herbicide availability and as a response to farm labor that is simultaneously aging and shrinking (USDA ERS, 2020). A survey conducted by the Agricultural Journal indicated that $56 \%$ of farmers had not been able to hire employees they needed during the last five years, and $70 \%$ had more trouble finding workers in 2017 and 2018 (Hamann, 2021). The implementation of successful robotic weeders will be nuanced, and factors such as the size of the operation, annual rainfall, and type of crop drive what type of robotic systems they will be willing to purchase.

The three most significant obstacles for widespread adoption of robotic weed control technology include: i) optimizing machine vision-based divergent recognition between crop and weed; ii) development of a wide range of weed control actuators, and subsequent flexibility to use multiple actuators with the same robotics system; iii) development of robotic systems that use small autonomous unmanned ground vehicles (UGV) that are affordably priced and can move into fields with higher soil moisture conditions since mechanical cultivators will likely be one of the more common actuators that will be fitted to autonomous weeders.

\section{Machine vision}

Weed detection using machine vision refers to the autonomous differentiation between weeds and crops. Commercial robotic weeders currently rely on traditional 2-dimensional-machinevision techniques combined with global positioning system (GPS) (Fennimore et al. 2016). Processing 2-D imagery requires deciphering a combination of plant spectrum by colour or infrared to red light reflectance ratios and crop differentiation from weeds by plant size and recognition of the commodity planting pattern (Slaughter et al., 2004; Slaughter et al., 2008). In annual crops, these techniques work best during the early growing season, before canopy closure has occurred, and while the crop is small enough that the leaves do not overlap. To maximize operational capacity, machine-vision guidance systems require a uniform, well-established crop monoculture, reduced weed density, and uniform crop plants greater in size relative to the weeds.

Nevertheless, innovation will be required to increase the affordability and efficiency of these devices. The challenge for machine vision is to discriminate weed from crop accurately. The presence of lighting variations, dynamic leaf architecture, and indistinguishable colour differences between weed and crop make this a daunting task. The system will ideally be able to calculate the total leaf area in individual scans in real-time, including uploading the seeding plan. The machine vision user interface enables the driver to keep track of the areas of the field scanned easily. Data logistics will be able to handle large areas for mapping purposes and allow for seamless recognition of field dynamics in successive visits, including algorithms that adjust for increased crop growth. Data should be easily exportable to comma separated values (CVS) format, which is a diagnostic information file. Finally, machine vision systems should be fully supported by software that will be updated frequently.

\section{Robot software}

One software system that has the potential to work well is robot operating system (ROS). ROS is a Berkeley source distribution (BSD) licensed system for controlling robotic components from a personal computer (PC). A ROS system consists of some independent nodes, each of which communicates with the other nodes using a publish/subscribe messaging model.

\section{Global positioning system guidance}

Due to the smaller size of the crop during its critical weed-free period, i.e., smaller plants are more susceptible to emerging weeds (Lanini and LeStrange, 1991), precise guidance of sensors and actuators will be necessary for robotics systems to succeed in the future (Lamm et al., 2002). The preferred technology for precise lateral guidance in crops is real-time kinematic (RTK) GPS technology . These systems provide auto guidance of the tractor, UGV, or UGV-UAV integrated systems. In a UGV integrated system, the UAV relays images of vegetation to the UGV to account for crop growth from the seeded/transplanted GPS system, which increases decision speed for the UGV. Modern RTK-GPS guidance systems are typically compatible with global navigation satellite systems from multiple countries to increase the total number of satellites available and improve reliability. The accuracy of RTK-GPS location measurement is within $3 \mathrm{~cm}$ relative to a specific geodetic datum (USGS, 2019). Under moderate weed infestation levels, machine vision guidance systems can outperform RTK-GPS guidance systems because they are more accurate (Slaughter et al., 1999) and because they are typically set up to control the lateral positioning of the cultivation system/weed control actuators directly, rather than indirectly through control of the tractor. However, at high weed infestation levels, machine-vision guidance systems can become unreliable (Slaughter et al., 1999). The convenience of having one guidance system for all farming operations (e.g., tillage, planting, harvesting) and the independence of the performance of RTK-GPS from the weed densities/size mean RTK-GPS guidance system will likely become the predominant technology for precise lateral guidance of automated weed control platforms.

\section{Actuator technology}

Actuators consist of devices such as cultivators that uproot weeds, those that damage weed foliage with propane burners, lasers, or steam, hammer drill, others such as abrasives that physically degrade weed foliage, and mowers that cut weeds. Weed detection systems and processors signal the actuator to target the weed but not the crop.

\section{Physical weed removal}

Four primary physical weed control actuators may be coupled with a weed detection system: i) mechanical intra-row and interrow cultivation; ii) thermal weed control; iii) abrasion; and iv) mowing. All of these methods have the advantage of being physical pest control devices as defined by the United States Environmental Protection Agency (USEPA), as well as the organization for Economic Co-operation and Development (OECD) members and are not regulated as pesticides (Fennimore and Cutulle, 2019). Thus, physical weed control devices also have the advantage of being compatible with organic production standards; thus they are useful in organic agriculture. With the exception of abrasion, many physical weed removal methods have been used 
for decades on guided cultivators, weed flamers, or mowers. Automation is a means to take a proven weed control device like a cultivator knife and combine it with intelligent technology to create something unique - a smart weeder. Several weeding devices are on the market, and more are possible as technology advances.

\section{Electrical weed control actuators}

Selective post-emergent broadleaf weed control is challenging in conventional vegetable systems and practically impossible in organic vegetable production systems (Kemble et al., 2021). Electrical weed control actuators such as the Weed Zapper (The Weed Zapper, Sedalia, MO, USA) utilize an electrified bar that can be attached to a tractor-based robotic weeding system pulled over the crop (weed zapper). The overhead bar can elect weeds that escape above the crop canopy, and the current travels down to the weed root system. Additionally, the weed zapper can be used in row middles, which would cut down on herbicide use in conventional vegetable systems and cultivation in organic. The reduced herbicide inputs and cultivation in row middles that would occur if weed zapper use became more abundant would reduce the amount of chemical residues and erosion in the field.

\section{Directed flame weed control}

Flame-directed weed control is relatively inexpensive, as propane is the primary fuel source (Stepanovic et al., 2016). Furthermore, flame weeding uses the plant's own carbon source as fuel for ignition, which lowers the energy required to control the weed compared to other thermal inputs. Directed flame application is most effective on weeds with a broad surface, such as larger broadleaf weeds, and is less effective on grassy weeds (Stepanovic et al., 2016). A drawback of flame weeding is the potential for injury and unintentional fires starting on dry ground (Cutulle et al., 2013).

\section{Cryogenic technology}

A new technology utilizing directed foliar cryogenic material followed by mechanical compaction pressure might be an effective option for weed control in row middles of horticultural crops (Cutulle et al., 2013). Cryogenic materials such as liquid nitrogen flash freeze plant tissues on contact to effectively rupture cell membranes and induce plant injury. Freezing injury is believed to result from disturbance to the plasma membrane, precipitation of plant proteins, ice formation in the extracellular solution, $\mathrm{pH}$ alteration, and the formation of gas bubbles. The gas bubbles can impact stationary protoplasts, which trigger the nucleation of super-cooled protoplasts and can subsequently damage plant cells. The purpose of mechanical pressure after freezing would be to further macerate the frozen cell membranes. The use of cryogenic material for weed control would involve no pesticides, lessen the need for intensive manual labour, have no fire hazards, and reduce soil erosion. However, results from previous studies utilizing cryogenic materials for weed control have been varied. Generally, liquid nitrogen is more effective than carbon dioxide snow for flash freezing weeds. However, flash freezing alone does not always damage enough tissue to result in plant death. Gradual freezing and subsequent slow thawing of plant tissue are more damaging to the plant than flash freezing alone. Innovative application technology might help directed cryogenic applications reduce undesirable weed species in specialty crop production.

\section{Precision/smart spray applicators}

Smart sprayers combine machine vision and GPS to maximize application efficiency. Precision herbicide application can substantially reduce herbicide input and weed control costs in multiple horticultural systems. Intelligent spot-spraying systems predominantly rely on machine vision-based detectors for autonomous weed control. Ecorobotix's prototype (Avo) precision micro sprayer uses $90 \%$ less herbicide when compared to broadcast applications. Reliance on solar power allows the Ecorobotix sprayer system to act autonomously concerning energy consumption, even when the weather is overcast. However, this system is not perfect. The robot's speed is negatively correlated to the concentration of weeds; it is most suitable for use in fields where the level of concentration is low to moderate to cover the ground at a reasonable speed. The manufacturers recommend using the machine after an initial standard application of herbicide to replace subsequent applications and thus save a significant amount of herbicide. The machine can be controlled entirely and customized utilizing a smartphone application. Other smart spray systems include joint venture projects between BASF and Bosch robotics. Bosch smart camera technology is incorporated into BASFs (Xarvio) digital farming software platform. These two products are to be integrated into intelligent planting solution (IPS) software, with improved computer intelligence for precision seed applications and fertilizer injections with smart spraying. Both products have been tested extensively in real growing conditions. The apparent drawback is that the systems only appear to be fitted for tractormounted systems rather than UGVs.

\section{Unmanned ground vehicles robotics platform}

Tractor-mounted autonomous weeders have been successfully implemented in California and parts of Europe (Fennimore and Cutulle, 2019). Robovatorä (Pacific Ag Rentals, 4 Harris rd, Salinas CA) is one of the more popular intelligent weeders used in California. Robovator is mounted to a PTO drive, contains static knives, mobile cultivating knives, camera, light, velocity sensor, and built-in RTK-GPS (personal communication with Steve Fennimore). Robovator significantly reduced weed density by 5 times relative to the control and decreased hand weeding time to $1 / 6^{\text {th }}$ of the time it took to weed the control plot. Though Robovator technology is widely used in California organic and conventional lettuce, broccoli, and spinach farms, this technology has some drawbacks. Robovator costs approximately US $\$ 140,000$, which would be too expensive for many small organic growers throughout the world. Furthermore, the high annual rainfall and soil moisture in some regions of the world make it difficult to navigate tractor-based cultivation systems through the field. Thus, there is a need to develop smaller UGV based weed management platforms.

UGVs have been used for different purposes in agriculture. BoniRob (Bosch, Postfach 300220, 70442 Stuggart, Germany) is a four-wheeled-steering robot with adjustable track width and used as a crop scout (Bangert et al., 2013). Its sensor suite includes different cameras (3D time of flight, spectral) and laser distance sensors. It was first designed as a phenotyping robot, but additional functionality was added as a weeder (personal communication with Bosch Robotics). It used a hammer type of mechanism to destroy weeds. Unfortunately, BoniRob development was discontinued for unknown reasons. Vinobot is a phenotyping UGV implemented on a popular mobile platform from Clearpathrobotics (personal communication with Erica Evans, Clearpathrobotics). Vinobot can measure phenotypic traits of plants using various sensors (Shafiekhani et al., 2017). TERRA-MEPP (transportation energy resource from renewable agriculture mobile energy-crop phenotyping platform) is another UGV used for high-throughput phenotyping of energy sorghum. It used imaging sensors to mea- 
sure plants from both sides as it traverses within rows, thereby overcoming the limitations of bigger UGV (Young et al., 2019).

UGVs are becoming more integrated into the manufacturing industry. Though most of the manufacturing environment is not as complicated as the outdoors, recent advances with sensors and algorithms provide an interesting outlook towards how robots will be working outdoors with humans. Commercial small UGV or mobile ground robots with navigation sensing modality provides a platform to increase farm management efficiency. The platform, Husky (Clearpathrobotics), can be retrofitted with different manifolds that perform specific tasks, e.g., spraying, scouting (having multiple sensors), phenotyping, weeding, harvesting, etc. An autonomous map-based robot navigation was developed, and a selective harvesting proof-of-concept was also designed and fieldtested in 2018 at Clemson University, Edisto Research, and Education Center (Blackville, SC, USA). The robot was retrofitted with a vacuum-type system with a small storage bin. Performance evaluation for the cotton harvesting was performed in terms of how effective the harvester suctions off the cotton bolls and the effective distance at which the operation is performed. Using the same robotic platform, a second weeding module was developed and tested in 2019 and 2020 that can be used for precision pesticide applications.

\section{Husky robotics platform experiment-a case study}

The robot used in this work is the Husky A200 (Figure 1) from Clearpathrobotics. The robot is suitable for field operations, as its width of $68 \mathrm{~cm}$ fits standard cotton row spacings. It is lightweight $(50 \mathrm{~kg}$ ) for field traffic, and thus soil compaction could potentially be reduced when compared to tractor-based or other larger farm cultivation machines. The robot is powerful enough to handle tow capacity payloads of up to $75 \mathrm{kgs}$ and can travel at speeds of 1 meter per second. It has a $24 \mathrm{~V} 6 \mathrm{Ah}$ Lead-acid battery which can provide 2 hours of operation. Two new lithium polymer batteries with 6 cells each and a 10Ah rating provide up to 3 hours of operation. Husky is equipped with an inertial measurement unit (IMU) (CHR-UM7, CH Robotics, Australia), GPS (Novatel Smart6-L, Novatel, Canada), individual steering motors and encoders for each wheel for basic navigation, and a light detection and ranging (LIDAR) laser scanner (UST-10LX, Hokuyo, Japan) for obstacle detection. The robot can be programmed to perform specific tasks like mapping, navigation, and obstacle avoidance through its onboard PC (mini-ITX) running on Ubuntu 16.04 operating system and the robot operating system (ROS, Kinetic version) framework. A mini-LCD screen, keyboard, and pointing device were connected to the onboard PC, allowing the user to write and test code and view and perform operations easily.

\section{Field navigation}

Autonomous field navigation is achieved by having a digital field map and localizing the robot on that map. Localization involves integrating the coordinate frame of the robot with the coordinate frame of the digital map. The robot's coordinate frame, commonly called its odometry, estimates its position and orientation over time. The accuracy of the robot's odometry may be enhanced by integrating it with other positional readings from an IMU or a GPS device.

\section{Robot operating system navigation stack}

The ROS Navigation Stack is an integrated framework of individual software or algorithmic packages bundled together as nodes for steering the robot from one point to the next. Users configure the navigation stack by either plugging in built-in or custom-built packages in any of the nodes of the navigation stack. Estimation of the robot's odometry is therefore handled internally by the nodes in the navigation stack that automatically loads, references, and updates the configuration file during runtime execution of the robot.

\section{Study site}

The field trials occurred at two separate locations, Edisto Research and Education Center [Edisto-REC] (33⒉ '26.6”N, $\left.81^{\circ} 19^{\prime} 39.9^{\prime \prime} \mathrm{W}\right)$ and Coastal Research and Education Center $\left(32^{\circ} 47^{\prime} 27.2^{\prime} \mathrm{N}, 80^{\circ} 03^{\prime} 37.6^{\prime \prime} \mathrm{W}\right)$ [Coastal-REC] of Clemson University in the months of July August of 2018, 2019, and early 2020. Prior to the field trials, the navigation of the mobile robot was tested. The row spacing of the sweet potato plants was approximately $91 \mathrm{~cm}$ and $15 \mathrm{~cm}$ in-row plant spacing. Transplanting was conducted in early May and harvesting in the first week of November. Regular crop management practices were applied during the growing season.

The mobile robot was tested twice per month through 5000 sq. m., without critical issues on the platform during the field trials. Most of the issues during the trials were attributed to the mechanical vibrations that loosen the IMU from its holder, wheel nuts, and the ball joint holder loosening. The issue with loose IMU was not detected early on as its location was obscured. ROS has a useful command line, rosbag, which can be used to record and replay .bag files. A bag file is a file format in ROS for storing data. Examining the files provides a clue why the mobile robot was acting abnormally on some of the preliminary tests. The abnormal performance included variation in automated travel speed and infrequent stops in-between waypoints.

Two different weeder modules were designed, built, and tested. The first design was $\mathrm{V}$-shaped, which had six individual prongs on each side, where each prong measured approximately $13 \mathrm{~cm}$. The prong was designed to penetrate $3.8 \mathrm{~cm}$ ( 1.5 inches) into the soil. Two wheels were used to ensure the prongs would be kept at a constant depth into the ground. In addition, a slider mechanism was designed to make the width of the two-prong holder adjustable. The second weeder was an adjustable harrow disk, where the disk holder can be adjusted at certain angles with no wheels to support the disk. Since the disk used was off-the-shelf, it was retrofitted with two wheels to minimize the force needed by the mobile robot to pull the weeder.

Early field tests demonstrated that the GPS device accuracy is very important, especially when the plants are in the early stages of crop growth. The LIDAR data did not provide any useful information, as the height of the plants was below the laser height. Due to the inaccuracy of using a Novatel GPS, a new GPS (Piksi Multi, Swift Navigation, USA) was used. A new configuration of the nodes and topics were created to integrate the new GPS with the waypoint navigation with the following tasks: i) reconfiguration of the different GPS nodes and topics for the GPS waypoint navigation code; ii) conversion of aerial view map (GeoTIFF image) to customized map used for navigation; iii) writing a python script to convert latitude and longitude points for each pixel in the GeoTIFF image; iv) exporting latitude and longitude points and overlaying them to GeoTIFF image pixels in Q geographic information system (QGIS, QGIS project), an open-source GIS software package.

\section{Weeder field trials}

The soil moisture average on the two-month trial was around $20 \%$. As shown in (Table 1), results indicate that the mobile robot's 
travel times were the same for both dry and wet soil. The same test was replicated with the weeder attached, and the results demonstrated an average travel time with wet soil is similar to without the weeder, but there was a significant increase in travel time with the weeder on dry soil, likely attributed to the cultivator having difficulty cutting through weeds in dry soil (Table 2).

The V-shaped weeder was not effective in weed control during the preliminary test. A weight was added to maintain soil penetration but its connection to the hitch eventually broke. Subsequent weed control trials focused on the harrow disk. Approximately $10 \sim 15 \%$ weed control was observed at the Edisto-REC field trials. Three different weeds were found in this area (Eleusine indica, Amaranthus palmeri, and Portulaca oleracea). The terrain in this location is not flat, which likely resulted in reduced weed control, presumably due to the challenges of controlling established weeds with reduced cultivator contact with the weed soil system. The Coastal-REC field trials resulted in higher weed control was observed $(80 \%)$. Note that the robot was tested on two different ground covers, and the terrain on this location was flat. For this UGV system to be successful significant improvements are needed to improve the cultivator system. Based on the results of this study improving weight distribution across the UGV-cultivation system should be prioritized to ensure maximum contact of the cultivator with the soil surface. Future research will also focus on including more mobile cultivation knives and other actuators such as electrocution-based or thermal applications.

Table 1. Impact of terrain type and soil moisture on robot speed (no crop).

\begin{tabular}{lcc} 
Terrain type & Soil moisture & $\begin{array}{c}\text { Travel speed } \\
\text { (kilometres per hour) }\end{array}$ \\
Smooth & $5 \%$ & $1.5^{\mathrm{b}}$ \\
Smooth & $20 \%$ & $1.75^{\mathrm{a}}$ \\
\hline Undulating & $5 \%$ & $1.52^{\mathrm{b}}$ \\
Undulating & $20 \%$ & $1.72^{\mathrm{a}}$ \\
\hline
\end{tabular}

a,bMeans within the same column with the same letter group are not significantly different according to Fisher's protected LSD.

\section{Future of unmanned ground vehicles based weed control}

This small experiment demonstrates the potential that the Husky robotics platform has with regard to controlling weeds. The UGV was able to move in soil moistures that would make tractorbased cultivation weed management difficult. The base model price for this UGV system is around $\$ 20,000$, which is significantly less than the cost of a new tractor-based cultivation system and would not require an operator each time it is deployed in the field. Rigorous experimentation is needed to determine the best set of actuators that could be fitted to UGV systems. The optimal UGV system will be adaptable to multiple crops through diverse actuator accessibility and multiple machine learning programs and sensors. These advancements are being made. However, reliance on machine vision for weed management without integrating other techniques limits this fledgling technology.

Since the dawn of agriculture, weeds have adapted to the selection pressure of human hand weeding through the selection of phenotypes mimicking crops during the critical weed-free period of the crop. This phenomenon is known as Vavilovian mimicry (McElroy et al., 2014). The Vavilovian mimicry theory involves multiple components that include a model, which is the crop that is being imitated; the mimic or the weed that is imitating the model; and the operator, whose job it is to discriminate between the model

Table 2. Impact of terrain type and soil moisture on robot speed with a cultivator.

\begin{tabular}{lcc} 
Terrain type & Soil moisture & $\begin{array}{c}\text { Travel speed } \\
\text { (kilometres per hour) }\end{array}$ \\
Smooth & $5 \%$ & $0.8^{\mathrm{b}}$ \\
Smooth & $20 \%$ & $1.7^{\mathrm{a}}$ \\
\hline Undulating & $5 \%$ & $0.6^{\mathrm{b}}$ \\
Undulating & $20 \%$ & $1.6^{\mathrm{a}}$ \\
\hline
\end{tabular}

a,bMeans within the same column with the same letter group are not significantly different according to Fisher's protected LSD.

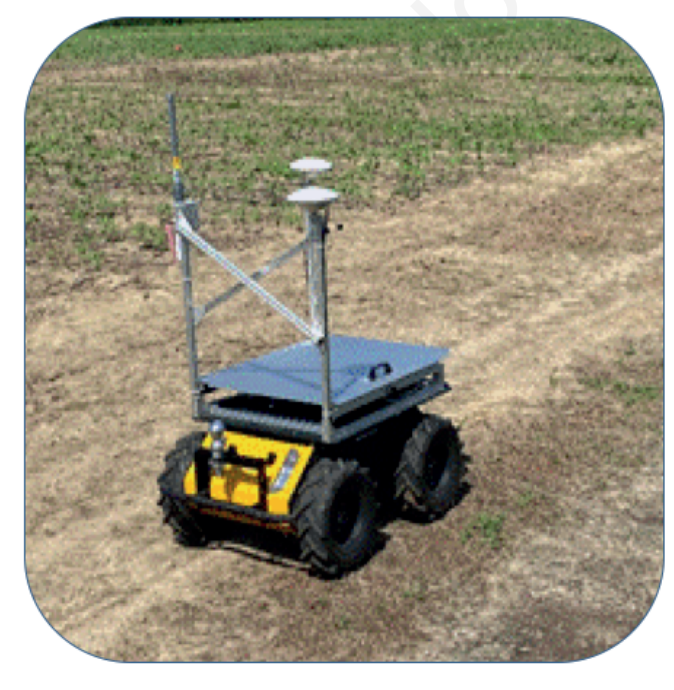

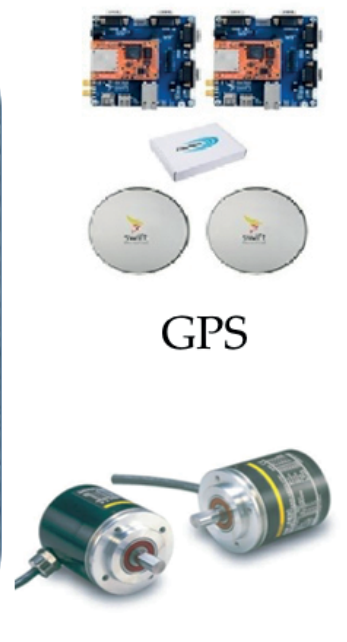

Encoders

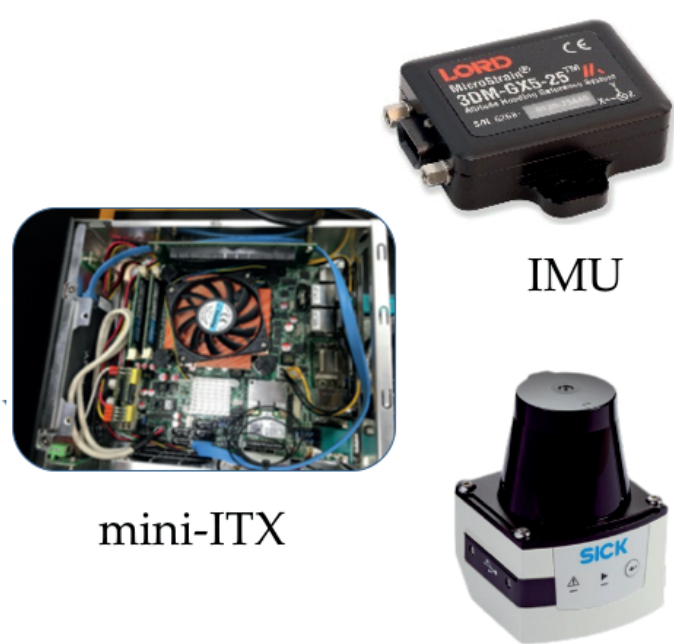

LIDAR

Figure 1. Mobile robot platform used in this project. 
and the mimic. Examples of the operator can be a human hand, herbicide spot spray applications, or a robot. Specific examples included hand weeding induced selection pressure on barnyardgrass (Echinochloa crus-galli) biotypes in rice fields in Asia that have evolved over hundreds of years. To prevent evolved mimicry in weeds, it may be essential to maximize the efficiency of machine vision by including IR and plant volatile sensors in addition to digital image analysis. RTK-GPS mediated cultivation will provide another 'operator' and lessen selection pressure on weeds that are not immediately proximal to the plant during the early stages of crop growth. Cultural practices, such as cover cropping and crop rotation, must also be implemented to avoid mimicry in weeds managed by robotic systems. There is tremendous potential for UGV based autonomous weed control, but proper stewardship will be required for this technology to be sustainable.

\section{References}

Avo. Available from: https://www.ecorobotix.com/en/avoautonomous-robot-weeder/ Last accessed: 02 May 2021.

Bangert W, Kielhorn A, Rahe F, Albert A, Biber P, Grzonka S, 2013. Field-robot-based agriculture: "RemoteFarming.1" and "BoniRob-Apps". pp 439-445 in AgEng, Internationale Tagung Land.Technik, Düsseldorf, Germany: VDI-Verlag.

Cutulle M, Armel G, Brosnan J, Kopsell D, Hart W, Vargas J, Gibson L, Messer R, McLemore A, Duncan H, 2013. Evaluation of a cryogenic sprayer using liquid nitrogen and a ballasted roller for weed control. J. Testing Evaluat. 41:869-74.

Cutulle M, Campbell H, Couillard D, Farnham M, 2019. Pre-plant herbicide application and cultivation to manage weeds in southeastern broccoli production. Crop Prot. 124:104862.

Clearpathrobotics. Available from: https://www.clearpathrobotics.com Accessed: 02 May 2021.

Ditlevsen K, Denver S, Christensen T, Lassen J, 2020. A taste for locally produced food-values, opinions and sociodemographic differences among 'organic' and 'conventional' consumers. Appetitie. 147:104544.

Fennimore SA, Slaughter DC, Siemens MC, Leon Saber MN, 2016. Technology for automation of weed control in specialty crops. WeedTechnol. 30:823-37.

Fennimore S, Cutulle M, 2019. Robotic weeders can improve weed control options for specialty crops. Pest Manage. Sci. 75:1767-74.
Hamann E, 2020. Amid rising costs and limited availability, farmers struggle to find enough workers. Business of Agriculture 2020. Available from: https://www.bizjournals.com/ sacramento/news/2020/04/24/amid-rising-costs-and-limited-availability-farmers.html Accessed: 02 May 2021.

Lanini WT, LeStrange M, 1991. Low-input management of weeds in vegetable fields. Calif. Agric. 45:11-3.

Lamm RD, Slaughter DC, Giles DK, 2002. Precision weed control system for cotton. Trans. ASAE. 45:231-8.

McElroy JS, 2014. Vavilovian Mimicry: Nikolai Vavilov and his little-known impact on weed science. Weed Sci. 62:207-16.

Mennan H, Ngouajio M, Isik D, Kaya E, 2009. Effects of alternative winter cover cropping systems on weed suppression in organically grown tomato (Solanum lycopersicum). Phytoparasitica. 37:385-96.

Shafiekhani A, Kadam S, Fritschi BF, DeSouza NG, 2017. Vinobot and vinoculer: Two robotic platforms for high-throughput field phenotyping. Sensors 17:214.

Slaughter DC, Giles DK, Fennimore SA, Smith RF. 2008. Multispectral machine vision identification of lettuce and weed seedlings for automated weed control. Weed Technol. 22:378-84.

Slaughter DV, Lanini WT Giles DK, 2004. Discriminating weeds from processing tomato plants using visible and near-infrared spectroscopy. Trans. ASAE 47:1907-11.

Slaughter DC, Chen P, Curley RG, 1999. Vision guided precision cultivation. Precis. Agric. 1:199-216.

Steponavich S, Datta A, Neilson B, Bruening C, Shapiro CA, Gogos G, Knezevic SZ, 2016. Effectiveness of flame weeding and cultivation for weed control in organic maize. Biol. Agric. Hortic. 32:47-62.

USDA NASS, 2020. United States Department of Agriculture National Agricultural Statistic Service. Available from: https://www.nass.usda.gov

USDA ERS, 2020. United States Department of Agriculture Economic Research Service. USDA ERS - Farm Labor. Accessed: November 2020.

USGS United States Geological Survery, 2019. Available from: https://www.usgs.gov

Weedzapper. Available from: https:/theweedzapper.com/ Accessed: 02 May 2021.

Xarvio. Available online: https://www.xarvio.com/us/en.html Accessed: 02 May 2021.

Young S, Kayacan E, Peschel J, 2019. Design and field evaluation of a ground robot for high-throughput phenotyping of energy sorghum. Prec. Agric. 20:697-722. 